\title{
High ferritin in homozygous and heterozygous $\beta$-thalassemia tends to decrease oxidative stress levels
}

\author{
Ani Melani Maskoen**, Lelani Reniarti**\#, Nur Imaniati Sumantri***, \\ and Edhyana Sahiratmadja ${ }^{\dagger}$
}

\begin{abstract}
\section{BACKGROUND}

Ineffective erythropoiesis and multiple blood transfusions may cause iron overload, leading to high level of ferritin in $\beta$-thalassemia patients. Iron has the ability to catalyze the production of reactive oxygen species (ROS), which can be prevented by an adequate activity of superoxide dismutase (SOD) and glutathione peroxidase (GPx). The aim of this study was to explore the association between high ferritin levels and oxidative stress among $\beta$-thalassemia patients by measuring SOD and GPx levels.
\end{abstract}

\section{METHODS}

This was a cross sectional study among $\beta$-thalassemia major patients. Ferritin, SOD, and GPx were measured and compared between $\beta$-thalassemia patients with homozygous IVS1nt5 and heterozygous IVS1nt5/HbE mutations, which were the most prevalent mutations found in our previous study. The Spearman correlation test was used to analyze the data.

\section{RESULTS}

The ferritin levels in all $\beta$-thalassemia major patients were very high (range: 791-12,340 $\mu \mathrm{g} / \mathrm{L})$. However, no significant differences were observed $(\mathrm{p}=0.318)$ between homozygous IVS1nt5 $(\mathrm{n}=45)$ compared to heterozygous IVS1nt5/HbE $(n=13)$. The oxidative stress markers SOD and GPx were not significantly different between homozygous IVS1nt5 and heterozygous IVS1 $1 \mathrm{t} 5 / \mathrm{HbE}$ ( $\mathrm{p}=0.450$ and $\mathrm{p}=0.323$, respectively). The correlations between ferritin and SOD and GPx oxidative stress levels were not significant in both homozygous IVS1nt5 and heterozygous IVS1nt5/HbE mutations.

\section{CONCLUSION}

High ferritin levels in $\beta$-thalassemia patients tend to decrease the GPx level in all thalassemia patients and SOD level in half of the patients, indicating that GPx and SOD may play a role in the occurrence of oxidative stress among thalassemia patients. The mechanism of oxidative stress in thalassemia needs to be further explored.

Keywords: IVS1nt5, HbE, superoxide dismutase, glutathione peroxidase, thalassemia patients
\#Joint first authors

*Department of Oral Biology, Faculty of Dentistry, Universitas Padjadjaran, Bandung, Indonesia **Department of Pediatrics, Dr. Hasan Sadikin General Hospital/ Faculty of Medicine, Universitas Padjadjaran, Bandung, Indonesia ***Biotechnology Master Program, Post Graduate School, Universitas Padjadjaran, Bandung, Indonesia 'Department of Biochemistry and Molecular Biology, Faculty of Medicine, Universitas Padjadjaran, Bandung, Indonesia

\section{Correspondence:}

Edhyana Sahiratmadja, MD, PhD

Department of Biochemistry and Molecular Biology, Faculty of Medicine, Universitas Padjadjaran Jl. Eijkman no. 38 Bandung Phone: +62816 996309

Email: e.sahiratmadja@unpad.ac.id

Date of first submission, January 29, 2018

Date of final revised submission, May 19, 2018

Date of acceptance, May 24, 2018

This open access article is distributed under a Creative Commons AttributionNon Commercial-Share Alike 4.0 International License

Cite this article as: Maskoen AM, Reniarti L, Sumantri NI, Sahiratmadja E. High ferritin in homozygous and heterozygous $\beta$-thalassemia tends to decrease oxidative stress levels. Univ Med 2018;37:97-104. doi: 10.18051/

UnivMed.2018.v37.97-104 


\section{INTRODUCTION}

Thalassemia is an inherited blood disorder due to a mutation in the $\alpha$ - or $\beta$-globin gene, leading to unbalanced globin chain synthesis. The $\alpha$ - and $\beta$-globin proteins are encoded by $\alpha$ and $\beta$ genes that lie on chromosomes 16 and 11 , respectively. ${ }^{(1)}$ Thalassemia is the most frequent monogenic disease in the world, and about $1.5 \%$ of the global population are heterozygotes or carriers of $\beta$-thalassemia. ${ }^{(2)}$ Half of these reside in Southeast Asian countries, where Indonesia harbors $0.1 \%$, with IVS1nt5 is being the most common $\beta$-thalassemia mutation. ${ }^{(3)}$

Beta-thalassemia major patients have mutations in both chains of the beta globin gene (homozygous), leading to a decrease in erythrocyte production, therefore requiring regular blood transfusion. ${ }^{(4)}$ Iron is absorbed in the intestinal tract and circulated in the blood. About half of the body iron makes up part of the red blood cell (RBC) composition and the other half is stored in ferritin or hemosiderin that is recycled during RBC destruction. ${ }^{(5)}$ Multiple transfusions increase iron absorption, leading to iron overload and its complications. Body iron and proteinbound iron such as serum iron, ferritin, and nontransferrin-bound iron (NTBI) may reflect the iron status of thalassemia patients. For example, ferritin is a strong indicator of iron deposit level. High levels of ferritin indicate iron overload, inflammation, malignancy, collagen disease, or liver disease. ${ }^{(6)}$ Therefore, thalassemia patients receiving multiple transfusions will have increased ferritin levels.

In $\beta$-thalassemia, ineffective erythropoiesis occurs as a result of unstable globin chains. Unpaired $\beta$-globin chains will form Heinz bodies. Hemoglobin subunit oxidation will cause hemichrome formation that influences hemolysis. Hemichrome then binds to band 3 proteins, ankyrins, spectrins, or other erythrocyte components. After that, hemichrome is precipitated, heme is disintegrated, and NTBI is released, leading to the formation of reactive oxygen species (ROS). ${ }^{(7)}$
Thus, iron plays a role as a catalyst in redox reactions, including the formation of ROS, such as superoxide $\left(\mathrm{O}_{2}^{-*}\right)$, hydrogen peroxide $\left(\mathrm{H}_{2} \mathrm{O}_{2}\right)$, and hydroxyl radical ( $\left.\mathrm{HO}^{*}\right)$, mainly through the Fenton reaction. ${ }^{(8)}$ At low levels, ROS play a role as a defense system against pathogens. Meanwhile, high levels of ROS exceed the antioxidant capacity, which is known as oxidative stress. This causes oxidative damage in lipids, proteins, DNA, or other cellular compartment damage. Antioxidant complexes will prevent oxidative damage by the cryopreservative cell system. ${ }^{(8)}$ Intracellular antioxidants prevent cell damage by oxygen and iron combination.

Antioxidants are classified into enzymatic and non-enzymatic antioxidants. Superoxide dismutase (SOD), glutathione peroxidase (GPx), catalase (CAT), and glutathione reductase (GR) are the major enzymatic antioxidants involved in scavenging ROS. ${ }^{(8)}$ Previous studies have measured SOD, GPx, CAT, malonyldialdehyde, ferritin, transferin, $\mathrm{Hb}$, vitamin $\mathrm{A}$, and vitamin $\mathrm{E}$ to determine the relationship between oxidative stress and $\beta$-thalassemia major, however, results were conflicting, ranging from lower to higher compared with normal controls. ${ }^{(9-11)}$

The combination of SOD and GPx is the main mechanism for superoxide detoxification in the cell, where SOD is a first-line defense endogenous enzyme that converts ROS, from superoxide $\left(\mathrm{O}_{2}^{-}\right)$to $\mathrm{H}_{2} \mathrm{O}$ and $\mathrm{H}_{2} \mathrm{O}_{2} \cdot{ }^{(12)}$ Glutathione plays an important role in erythrocyte defense, which catalyzes $\mathrm{H}_{2} \mathrm{O}_{2}$ to $\mathrm{H}_{2} \mathrm{O}$ or organic hydroperoxide to alcohol. Furthermore, GPx also has wide affinity range, making it an important system against ROS. ${ }^{(12)}$ The activity of SOD and GPx in $\beta$ - thalassemia patients may be lower than that in the control group. ${ }^{(11)}$ This is caused by high production of ROS that depletes those enzymes. Moreover, ROS also has the capability to damage DNA, proteins, and lipids in the cell, which includes antioxidant molecules. ${ }^{(12)}$ The activity of SOD may decrease 1.5 times in homozygous $\beta$ thalassemic children compared to non-hemolytic anemia controls. ${ }^{(10)}$ Superoxide radicals can trigger autooxidation of hemoglobin chains, which 
plays a role in hemolysis. Therefore, the measurement of SOD and GPx levels in $\beta$ thalassemia patients is important to assess the presence of oxidative stress. ${ }^{(11)}$

The aim of this study was to explore the association in $\beta$-thalassemia patients between high ferritin levels on the one hand and oxidative stress level SOD and GPx on the other. In this study, we have compared homozygous IVS1nt5 and heterozygous IVS1nt $5 / \mathrm{HbE}$ mutations of the $\beta$-globin gene, as these were prevalent in our thalassemia patients from Bandung, Indonesia. ${ }^{(13)}$

\section{METHODS}

\section{Research design}

This study was a cross sectional analysis among $\beta$-thalassemia patients recruited in the Thalassemia Clinic, Dr. Hasan Sadikin General Hospital in Bandung, Indonesia, during the year 2017.

\section{Research subjects}

The $\beta$-thalassemia patients were clinically diagnosed from the clinical history and the regular blood transfusions, and from laboratory tests, as well as deoxyribonucleic acid (DNA) screening, as described in a previous study. ${ }^{(13)}$ Total sampling was performed, thus all $\beta$-thalassemia patients with DNA mutation data in the clinic were asked to participate in this study upon written consent of their parents, since these patients were considered as a vulnerable group. Patients with heart failure, hepatitis, renal failure, nephrotic syndrome, and diabetes mellitus were excluded. $\beta$-thalassemia patients were then grouped into homozygous IVS1nt5 and heterozygous IVS1nt5/ $\mathrm{HbE}$, and ferritin level and antioxidant activity were measured and compared between the two groups.

\section{Hematological parameters}

A volume of $3 \mathrm{~mL}$ of blood was withdrawn aseptically from each of the subjects before they received blood transfusion. Blood was collected in a tube containing ethylenediaminetetraacetic acid (EDTA) for various regular standardized tests in the Dept. of Clinical Pathology of Dr. Hasan Sadikin General Hospital, including complete blood count (using a Sysmex XP-100 automated hematology analyzer, Japan) and determination of ferritin concentrations (SigmaAldrich, USA).

\section{Measurement of GPx and SOD antioxidant activity}

Enzymatic tests were performed at the Molecular Genetic Laboratory, Faculty of Medicine, Universitas Padjadjaran. About $0.5 \mathrm{~mL}$ of whole blood was centrifuged at $3000 \mathrm{rpm}$ for 10 minutes to separate the serum and the red blood cells (RBCs). The RBCs were washed using $3 \mathrm{~mL}$ of $0.9 \% \mathrm{NaCl}$ and centrifuged 3 times at $3000 \mathrm{rpm}$ for 10 minutes. The pellet was diluted with $2 \mathrm{~mL}$ of distilled water for SOD measurement (Ransod, RANDOX, Antrim-UK). The diluted sample for GPx measurement used $0.02 \mathrm{~mL}$ of whole blood mixed directly with the reagent from the kit (RANSEL, RANDOX, Antrim-UK). The samples were then run on a UV-visible spectrophotometer and the antioxidant activity was calculated.

\section{Statistical analysis}

The Kruskal-Wallis test was used to compare the level of oxidative stress (SOD and GPx) between the two $\beta$-thalassemia mutations i.e. homozygous IVS1nt5 and heterozygous IVS1nt5/HbE. A p-value of less than 0.05 was considered as the limit for the level of significance. The Spearman correlation test was used to analyze the relationship between the activity of both antioxidants.

\section{Ethical clearance}

The protocol of this study was approved and ethical clearance was granted by the Health Research Ethics Committee, Medical Faculty, University of Padjadjaran no.172/UN6.C10/PN/ 2017. 
Table 1. Characteristics of $\beta$-thalassemia subjects with homozygote IVS1nt5 mutation and heterozygote IVS1nt5/HbE mutation

\begin{tabular}{lccc}
\hline & $\begin{array}{c}\text { Homozygote } \\
\text { IVS1nt5 (n=45) }\end{array}$ & $\begin{array}{c}\text { Heterozygote } \\
\text { IVS1nt5/HbE (n=13) }\end{array}$ & p-value \\
\hline Age (year); mean(SD) & $11.0(4.2)$ & $13.4(5.8)$ & $0.459^{\mathrm{a}}$ \\
Hb level (g/dL); mean (SD) & $6.8(0.8)$ & $6.9(0.7)$ & $0.647^{\mathrm{a}}$ \\
Frequency of transfusion; n (\%) & & & \\
Every 2 weeks & $8(17.8 \%)$ & - & $0.019^{\mathrm{b}}$ \\
Every 3 weeks & $19(42.2 \%)$ & $3(23.1 \%)$ & \\
$\geq 4$ times weekly & $18(40.0 \%)$ & $10(76.9 \%)$ & \\
Iron chelator; $\mathrm{n}(\%)$ & & & \\
Deferoxamine (DFO) & $1(2.2 \%)$ & $4(30.8 \%)$ & \\
Deferasirox (DFX) & $15(33.3 \%)$ & $9(69.2 \%)$ & \\
Deferiprone (DFP) & $29(64.4 \%)$ & & \\
\hline
\end{tabular}

Note: ${ }^{\mathrm{a}}$-test analysis, ${ }^{\mathrm{b}}$ chi-square comparison $<4$ vs. $\geq 4$ times weekly; $\mathrm{p}$ value $<0.05$ is significantly different

\section{RESULTS}

In total, we have included 58 patients $\beta$ thalassemia in our study, consisting of patients with homozygous IVS1nt5 $(n=45)$ and heterozygous IVS1nt5/HbE ( $\mathrm{n}=13)$ mutations, with age ranges between 1 to 18 years and 2 to 26 years, respectively. The hemoglobin $(\mathrm{Hb})$ levels in the $\beta$-thalassemia subjects were generally found to be low, with a mean $\mathrm{Hb}$ level of $6.8 \mathrm{~g} /$ $\mathrm{dL}$, ranging from 4.53 to $8.28 \mathrm{~g} / \mathrm{dL}$. However, there was no significant difference in the severity of anemia between homozygous IVS1nt5 and heterozygous IVS1nt5/HbE, since the Hb level and age in both groups were not significantly different (Table 1). Furthermore, the frequency of transfusion in homozygous IVS1nt5 was higher compared to heterozygous IVS $1 \mathrm{nt} 5 / \mathrm{HbE}$ $(\mathrm{p}=0.019)$. Deferiprone (DFP) was the most used iron chelator in both groups.

The ferritin level in both homozygous and heterozygous groups was high (Table 2). All patients had low GPx levels, with a median value of $264.98 \mathrm{U} / \mathrm{mL}$ (range: $8.41-1,753 \mathrm{U} / \mathrm{mL}$ ) which was under the normal range of 4,171-10,881 U/ $\mathrm{mL}$. The median SOD level among the subjects was $170.65 \mathrm{U} / \mathrm{mL}$ (range: $54.51-276.26 \mathrm{U} / \mathrm{mL}$ ), which was within the normal range of 164-240 $\mathrm{U} / \mathrm{mL}$. However, when the individual values were dichotomized into low or normal value, it was

Table 2. Ferritin concentration and oxidative stress levels among $\beta$-thalassemia patients with homozygote IVS1nt5 and heterozygote IVS1nt5/HbE

\begin{tabular}{lccc}
\hline & $\begin{array}{c}\text { IVS1nt5 } \\
\text { Homozygote }\end{array}$ & IVS1nt5/HbE Heterozygote & p-value \\
\hline $\begin{array}{c}\text { Ferritin }(\mu \mathrm{g} / \mathrm{L}) \\
\text { Median }\end{array}$ & 3,784 & 3,555 & 0.318 \\
Range & $(791-12,340)$ & $(1,785-8,135)$ & \\
SOD $(\mathrm{U} / \mathrm{mL})$ & 172.12 & 167.55 & 0.450 \\
$\quad$ Median & $54.51-276.26$ & $94.31-228.94$ & \\
Range & $17(37.8)$ & $6(46.2)$ & 0.749 \\
Low; $\mathrm{n}(\%)$ & $28(62.2)$ & $7(53.8)$ & \\
Normal; $\mathrm{n}(\%)$ & & & \\
GPx $(\mathrm{U} / \mathrm{mL})$ & 227.1 & 319.6 & 0.323 \\
$\quad$ Median & $(8.4-1,329)$ & $(16.8-1,753)$ & \\
$\quad$ Range & & & \\
\hline
\end{tabular}

Note: "Normal range for ferritin $(12-300 \mu \mathrm{g} / \mathrm{L})$; \# Normal range for SOD $(164-240 \mathrm{U} / \mathrm{mL})$ and for GPx $(4,171-10,881 \mathrm{U} / \mathrm{mL})$; SOD: superoxide dismutase; GPx: glutathione peroxidase 


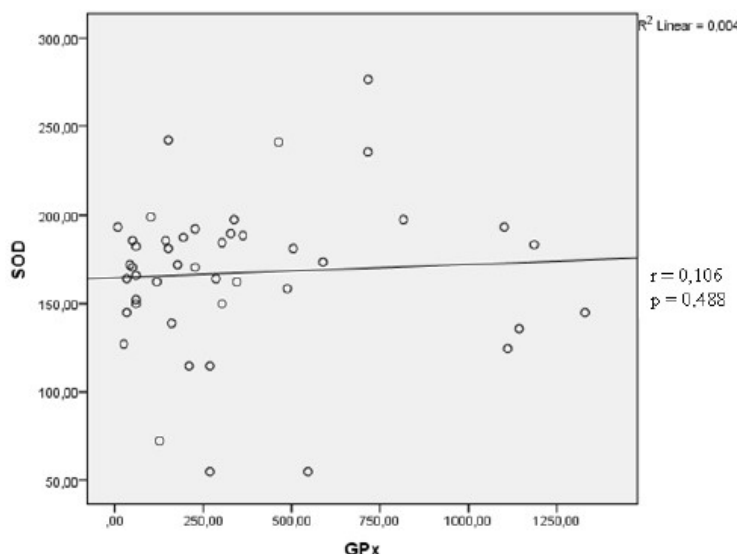

(a)

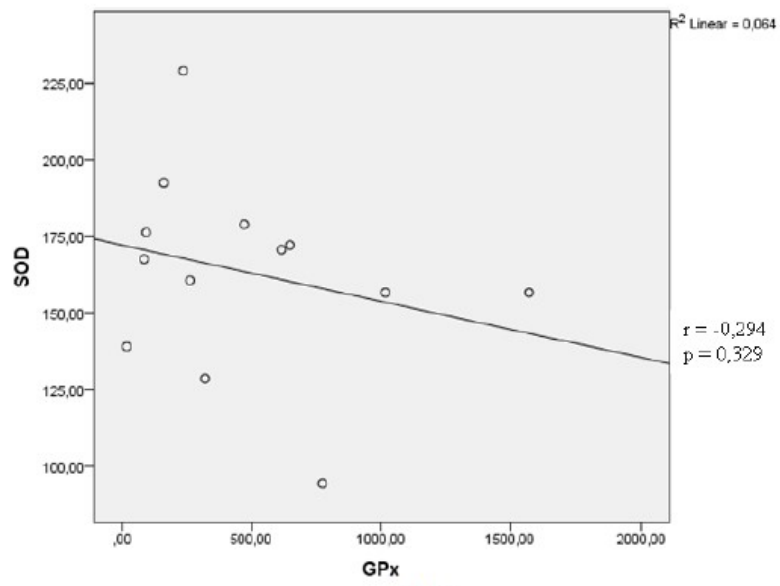

(b)

Figure 1. Correlation between superoxide dismutase (SOD) and glutathione peroxidase (GPx) activity in $\beta$-thalassemia patients with: (a) homozygous IVS1nt5 mutation and (b) heterozygous IVS1nt5/HbE mutation

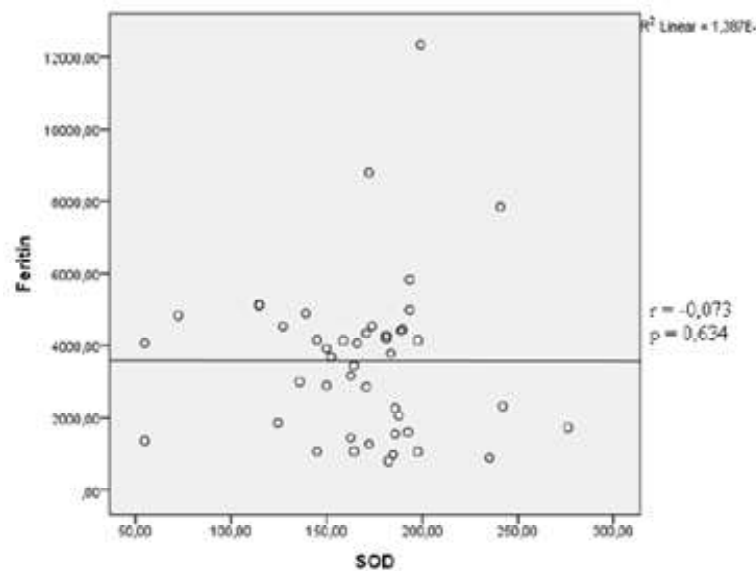

(a)

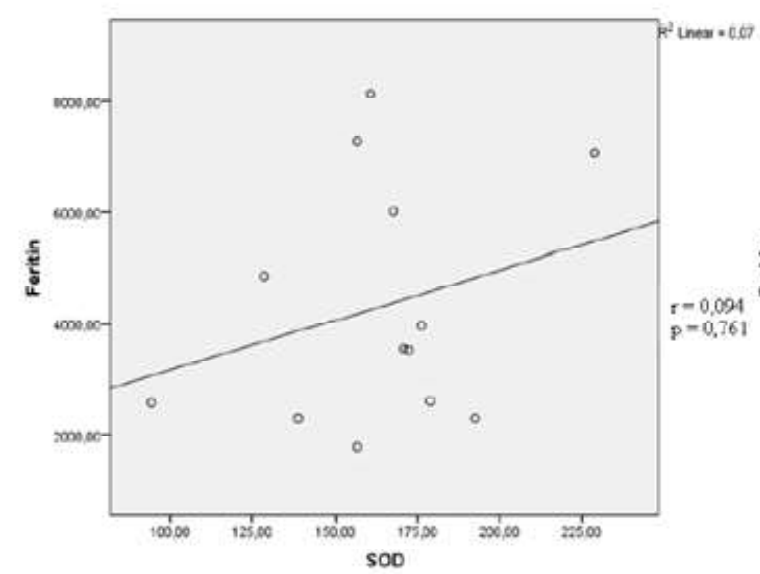

(c)

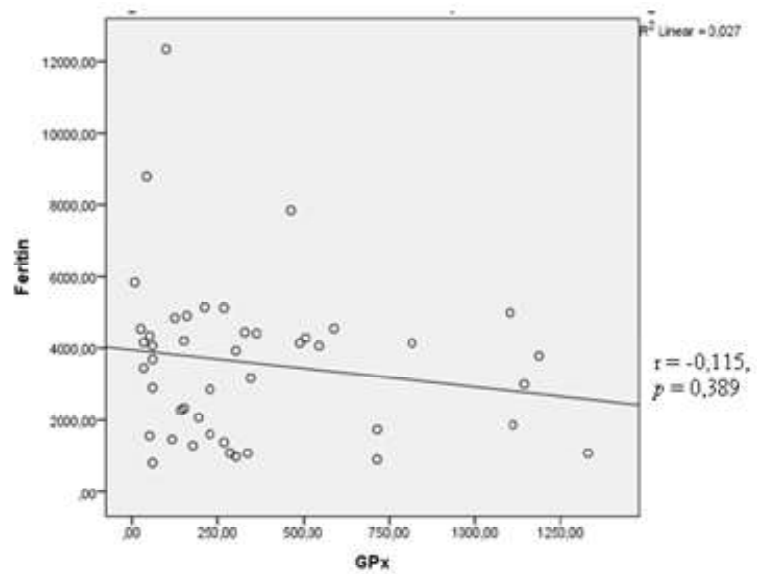

(b)

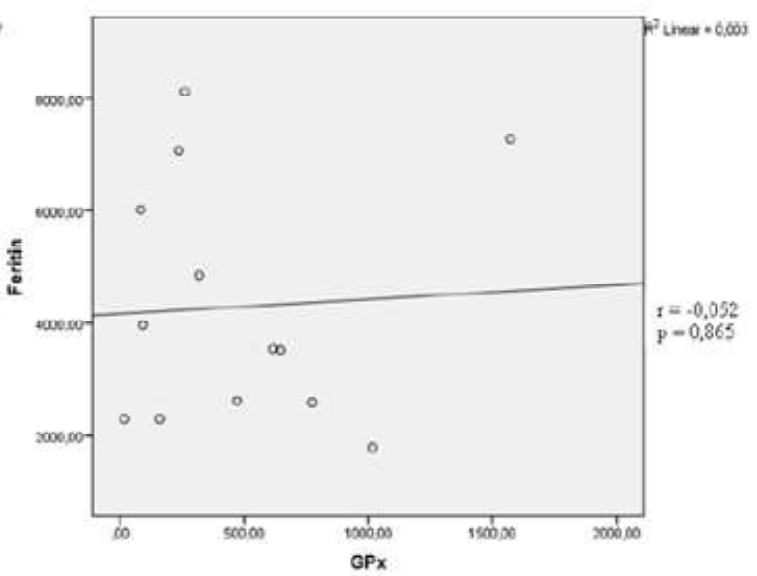

(d)

Figure 2. Correlation between ferritin levels and SOD activity in $\beta$-thalassemia patients with: (a) homozygous IVS1nt5 mutation or (c) heterozygous IVS1nt5/HbE mutation; and correlation between ferritin levels and GPx activity in $\beta$ thalassemia patients with: (b) homozygous IVS1nt5 mutation or (d) heterozygous IVS1nt5/HbE mutation (Spearman correlation analyses). Note. SOD: superoxide dismutase; GPx : glutathione peroxidase 
observed that half of the patients had low SOD levels. The levels of oxidative stress (GPx and SOD) did not differ significantly in homozygous IVS1nt5 compared to heterozygous IVS1nt5/ $\mathrm{HbE} \beta$-thalassemia patients (Table 2).

There was no association between SOD and GPx activities, both in the homozygous IVS1nt5 and heterozygous IVS 1 nt $5 / \mathrm{HbE}$ groups (Figure 1). Furthermore, there was also no association between the ferritin level and SOD or GPx antioxidant level in both groups (Figure 2).

\section{DISCUSSION}

In the province of West Java, the homozygous and heterozygous forms of IVS1nt5 are the most frequent mutations, with homozygous IVS1nt5 (49.25\%) and heterozygous IVS1nt5/HbE (8.89\%) being the two most prevalent, as described in a previous study. ${ }^{(13)}$ Patients with thalassemia have chronic anemia, and therefore require repeated transfusions. The frequency of transfusion in homozygous IVS1nt5 is higher compared to that in heterozygous IVS1nt5/HbE ( $\mathrm{p}=0.019)$. This is the opposite of the results from another study showing that the co-inheritance of IVS1nt5 in $\mathrm{HbE}$ patients may lead to more severe symptoms compared to homozygous IVS1nt5.(14)

Furthermore, repeated transfusions can result in iron overload. The ferritin levels in patients receiving repeated transfusions in this study is comparable in both groups, i.e. in the homozygous IVS1nt5 and the more severe heterozygous IVS $1 \mathrm{nt} 5 / \mathrm{HbE}$ groups. Since thalassemia patients have undergone repeated blood transfusions, the ferritin levels are higher when the RBCs are depleted, which does not necessarily depend on the type of mutation, resulting in a similar range of blood parameters such as ferritin between the two groups. ${ }^{(15)}$

One study in Indonesia showed that ferritin levels in heterozygous IVS1nt5/HbE patients were higher than in homozygous IVS1nt5 or without $\mathrm{HbE}$, confirming that the heterozygous type is the more severe. ${ }^{(16)}$ The more severe type of IVS1nt5 in heterozygous form was also discussed elsewhere. ${ }^{(17)}$ Interestingly, ferritin levels in heterozygous $\mathrm{HbE} / \beta$-thalassemia can be 40 times higher compared to that in the control group. ${ }^{(18)}$ These conflicting results between the various studies require further explorative and confirmative studies.

As in $\beta$-thalassemia major patients, ineffective erythropoiesis, apoptosis, and oxidative damage causes a shortened erythrocyte lifespan among $\mathrm{HbE} / \beta$-thalassemia patients. ${ }^{(18)}$ The levels of SOD and GPx activity in heterozygous $\mathrm{HbE} / \beta$-thalassemia are higher than in homozygous $\beta$-thalassemia and controls, and the increased SOD activity in $\beta$-thalassemia and $\mathrm{HbE} / \beta$-thalassemia occurs as a response against superoxide radicals, forming more hydrogen peroxide. ${ }^{(19)}$ Another study showed that SOD activity in $\beta$-thalassemia was higher than in controls, while that of GPx was lower than in controls. ${ }^{(20)}$ In contrast, all patients in our study, including those with homozygous IVS1nt5 $\beta$-thalassemia and heterozygous $\mathrm{HbE} / \beta$ thalassemia had normal GPx levels. On the other hand, although SOD levels in $\beta$-thalassemia are generally normal, approximately half of the subjects had low SOD levels (Table 2). The lack of comparison with healthy control subjects was a limitation in our study, as the levels of SOD and GPx were not evaluated in healthy controls, which is a notion for future studies.

This study showed that there was no association between SOD and GPx activity, both in the homozygous IVS1nt5 and the heterozygous IVS1nt5/HbE groups (Figure 1). Furthermore, there was also no correlation between the ferritin levels and SOD or GPx activity in both groups. Interestingly, other studies had shown a negative correlation between ferritin levels and SOD as well as GPx activity in anemic patients receiving repeated transfusions. ${ }^{(21,22)}$

The limitations of this study are related to the fact that the activities of SOD and GPx in the control group were not measured. Furthermore, we were hampered by several 
other limitations, such as the lack of data on iron chelator adherence, duration of treatment with chelating agents, and the degree of disease severity. Moreover, as this was a cross sectional study, age was not further explored in relation to the oxidative stress level.

The low SOD level in thalassemia patients suggests its role in thalassemia, therefore, studies should be directed towards determining the role of SOD as a potential therapeutic agent in thalassemia.

\section{CONCLUSION}

High ferritin levels in $\beta$-thalassemia patients tend to decrease the GPx level in all thalassemia patients and the SOD level in half of the patients, indicating that GPx and SOD may play a role in the occurrence of oxidative stress among thalassemia patients. The mechanism of oxidative stress in thalassemia needs to be further explored.

\section{ACKNOWLEDGEMENTS}

We would like to thank all participants, nurses, and the Organization of Thalassemia Patients and Parents (POPTI) for their participation in this study.

\section{COMPETING INTERESTS}

The authors declare that they have no competing interests.

\section{FUNDING}

This study was financially supported by the Fundamental Research Grant University of Padjadjaran for the year 2017.

\section{AUTHORS' CONTRIBUTIONS}

AMM and LR contributed equally to this paper. AMM and LR conceived and designed the experiments. AMM, LR, NIS, and ES participated in the design of the study and the interpretation of the data. NIS performed the experiments, NIS and ES conducted data analysis. AMM and NIS wrote the first draft, and reviewed by ES. All authors read and approved the final manuscript.

\section{REFERENCES}

1. Kumar R, Sagar C, Sharma D, et al. $\beta$-globin genes: mutation hot-spots in the global thalassemia belt. Hemoglobin 2015;39:1-8. doi: 10.3109/03630269. 2014.985831.

2. Colah R, Gorakshakar A, Nadkarni A. Global burden, distribution and prevention of betathalassemias and hemoglobin E disorders. Expert Rev Hematol 2010;3:103-17. doi: 10.1586/EHM. 09.74 .

3. Departemen Penelitian dan Pengembangan Kesehatan Departemen Kesehatan Republik Indonesia. Riset Kesehatan Dasar (RISKESDAS) 2007, Laporan nasional 2007. Jakarta: Departemen Penelitian dan Pengembangan Kesehatan Departemen Kesehatan Republik Indonesia; 2008.

4. Galanello R, Origa R. Beta-thalassemia. Orphanet J Rare Dis 2010;5. doi: 10.1186/1750-1172-5-11.

5. Kohgo Y, Ikuta K, Ohtake T, et al. Body iron metabolism and pathophysiology of iron overload. Int J Hematol 2008;88:7-15. doi: 10.1007/ s12185-008-0120-5.

6. Gozzelino R, Arosio P. Iron homeostasis in health and disease. Int J Mol Sci 2016;17:E130. doi: 10.3390/ijms17010130.

7. Patel M, Ramavataram DV. Non transferrin bound iron: nature, manifestations and analytical approaches for estimation. Indian J Clin Biochem 2012;27:322-32. doi: 10.1007/s12291-012-0250-7.

8. Pham-Huy LA, He H, Pham-Huy C. Free radicals, antioxidants in disease and health. Int J Biomed Sci 2008;4:89-96.

9. Mahdi EA. Relationship between oxidative stress and antioxidant status in beta thalassemia major patients. Acta Chim Pharm Indica 2014;4:137-45.

10. Rujito L, Mulatsih S, Sofro ASM. Status of superoxide dismutase in transfusion dependent thalassaemia. NAm J Med Sci 2015;7:194-8. doi: 10.4103/1947-2714.157480.

11. Asif M, Manzoor Z, Farooq MS, et al. Status of oxidant, antioxidant and serum enzymes in thalassaemic children receiving multiple blood transfusions. J Pak Med Assoc 2015;65:838-43.

12. Lu JM, Lin PH, Yao Q, et al. Chemical and molecular mechanisms of antioxidants: experimental 
approaches and model systems. J Cell Mol Med 2010;14:840-60. doi: 10.1111/j.1582-4934.2009. 00897.x

13. Maskoen AM, Rahayu NS, Reniarti L, et al. Mutation spectrum of $\beta$-globin gene in thalassemia patients at Hasan Sadikin Hospital West Java Indonesia. Cell Mol Biol (Noisy-legrand) 2017;63:22-4. doi: 10.14715/cmb/2017.63. 12.6.

14. Fucharoen S, Weatherall DJ. The hemoglobin E thalassemias. Cold Spring Harb Perspect Med 2012;2:a011734.

15. Jones E, Pasricha SR, Allen A, et al. Hepcidin is suppressed by erythropoiesis in hemoglobin $\mathrm{E}$ $\beta$-thalassemia and $\beta$-thalassemia trait. Blood 2015; 125:873-80. doi: 10.1182/blood-2014-10-606491.

16. Wahidiyat PA, Gatot D, Tjitrasari T, et al. Phenotypic diversity in beta-HbE thalassemia patients. Pediatr Indones 2006;46:82-6. doi: 10.14238/pi46.2.2006.82-6.

17. Sripichai O, Makarasara W, Munkongdee T, et al. A scoring system for the classification of $\beta$ thalassemia/Hb E disease severity. Am J Hematol 2008;83:482-4. doi: 10.1002/ajh.21130.
18. Aphinives C, Kukongviriyapan U, Jetsrisuparb $A$, et al. Impaired endothelial function in pediatric hemoglobin E/ $\beta$-thalassemia patients with iron overload. Southeast Asian J Trop Med Public Health 2014;45:1454-63.

19. Yanpanitch OU, Hatairaktham S, Charoensakdi R, et al. Treatment of $\beta$-thalassemia/hemoglobin $\mathrm{E}$ with antioxidant cocktails results in decreased oxidative stress, increased hemoglobin concentration, and improvement of the hypercoagulable state. Oxid Med Cell Longev 2015;2015. Article ID 537954, 8 pages. doi: $10.1155 / 2015 / 537954$.

20. Fernandes MS, Rissi TT, Zuravski L, et al. Oxidative stress and labile plasmatic iron in anemic patients following blood therapy. World $\mathrm{J}$ Exp Med 2014;4:38-45. doi: 10.5493/wjem.v4.i3.38.

21. Abdalla MY, Fawzi M, Al-Maloul SR, et al. Increased oxidative stress and iron overload in Jordanian $\beta$-thalassemic children. Hemoglobin 2011;35:67-79. doi: 10.3109/03630269.2010.544624.

22. Dhawan V, Kumar KR, Marwaha RK, et al. Antioxidant status in children with homozygous thalassemia. Indian Pediatr 2005;42:1141-5. 